Canadian Journal of Family and Youth, 11(1), 2019, pp. 162-179

ISSN 1718-9748@ University of Alberta

http://ejournals,library,ualberta.ca/index/php/cjfy

\title{
Slacktivism: \\ Not Simply a Means to an End, but a Legitimate Form of Civic Participation
}

\author{
Chantal Piat
}

\begin{abstract}
This paper explores the many forms of online activism, also known as "slacktivism," such as making small charitable donations, changing a social media profile picture, and using technological knowledge to hack websites. The effectiveness of slacktivism is investigated based on prior research in the field, as the nuances of activism, politics, and effectiveness itself are deconstructed. An argument is posed that any form of activism, whether it is performed online or offline, is valuable and legitimate regardless of its size or reach. It is known that small online acts of participation are strongly correlated with grander offline acts of participation. While it is important to acknowledge the value of offline activism such as participating in a protest or boycott, acts of slacktivism also have an inherent value in and of themselves. Slacktivism should not be written off as an ineffective "feel-good" tool that young people utilize, but rather as a legitimate form of social and political action.
\end{abstract}

Chantal Piat is an undergraduate student majoring in psychology and sociology at MacEwan University in Edmonton, Alberta. Her research interests include social justice, critical criminology, and social and political engagement. 
Piat

\section{Introduction}

In the "post-Trump" era in which we live, the topics of voting, political participation, and millennial apathy are ever-growing in both media and academia. With the Internet garnering more and more influence over the current generation of up-and-coming voters, it only makes sense that politics will make a larger appearance in that domain. Previous research has either denounced concepts like 'slacktivism' or has given credit to these micro forms of participation as serving their own kind of purpose separate from the arena of traditional activism. For example, UNICEF Sweden (2013) launched a “Likes Don't Save Lives” campaign to encourage people to make financial donations rather than simply liking or sharing social media posts to prevent childhood disease in developing countries. Even the term 'slacktivism' and its various subsets like 'clicktivism' and 'hacktivism' have a negative connotation of laziness, excessive ease of use, and in the case of hacktivism, illegality. We must also not overlook the ageism that dominates discussions about slacktivism, as the young Internet-age population is developing alongside technological advances and social and political activity. While youths who have strong computer skills certainly make up a large portion of online activists, many older generations partake in the same online surveys and political tweets as their younger counterparts.

This paper aims to explore several questions, including what specific forms of participation are legitimate and effective and what it even means to be "effective" when it comes to politics and social movements. Specifically, the various activities that may fall under the umbrella of slacktivism, such as changing a social media profile picture, making small charitable donations, and hacking corporate or political websites and databases will be evaluated to determine their effectiveness. Forms of activism that are typically described as 'slacktivism' certainly appear to have several pitfalls and benefits, as do traditional forms of political 
participation. We are in the Internet age with no end in sight, and with social media sites constantly evolving, so too evolve our forms of civic engagement. In this paper, I will decode the language surrounding slacktivism, as I determine adequate definitions of slacktivism, politics, and effectiveness. Then, I will investigate if slacktivism is a legitimate and effective form of political participation. In general, slacktivism has been shown to be correlated with subsequent offline participation, however, this paper will describe how slacktivism in and of itself is a valid and effective form of civic engagement.

\section{What is Slacktivism?}

Defining slacktivism as a whole tends to be difficult depending on who is leading the discussion. In the media and scholarly research, 'slacktivism' is used both as an umbrella term for several forms of low-scale activism like hacktivism, clicktivism, and small charitable donations, but it may also be used as an interchangeable term for 'clicktivism.' For the purposes of this paper, I will operate under the former definition of slacktivism. To further complicate discussion, many different definitions of slacktivism exist, with varying degrees of critique or support. For example, Kristofferson, White and Peloza (2013) define slacktivism as a willingness to engage in a small token act of support for a cause, while also being unwilling to “devote significant effort to enact meaningful change." This definition clearly has a negative slant, as it posits that any and all small supportive acts are not meaningful and cannot incite change. A description like this gives no room for the possibility of slacktivism being a legitimate and useful form of political engagement. Furthermore, the insinuation that individuals who engage in slacktivism are unwilling to participate offline simply because they are engaging in slacktivism is heavily disputed by empirical evidence. 
Piat

A much more neutral definition of slacktivism is presented by Leyva (2017), describing it as "low-risk, low-cost activities via social media whose purpose is to raise awareness, produce change, or grant satisfaction to the person engaged in the activity." Describing the intent and context behind slacktivist action is important. It is easy for critics conflate tweeting an innocuous update about one's day with sharing a news story about a pertinent social issue since they exist on the same platform. However, as young people are creating new and more connections online - perhaps even international connections - we must understand that these are real relationships. Online friendships can be as strong as in-person friendships and calling your friend to action in a face-to-face interaction is not necessarily the most effective route.

Furthermore, as we deconstruct what it means for activism to be considered "effective," Leyva's (2017) definition of slacktivism is preferred. While it is certainly useful for an issue if slacktivism leads to significant offline action, if a person engages in slacktivism simply to feel good, that action should not be deemed worthless. Leyva's (2017) description of slacktivism is slightly narrow, however, as it assumes that slacktivism occurs solely within the realm of social media. This may be the case for clicktivism, but many scholars consider small in-person donations or even signing a petition to be slacktivist actions. It is important to consider the fact that slacktivism - and activism in general for that matter - exists on a spectrum with a variety of political actions ranging in difficulty and outcome.

\section{Clicktivism}

The most accessible and widely used form of slacktivism is "clicktivism." Halupka (2018) describes clicktivism as "the use of social media, social buttons, and similar lowthreshold activities to engage in politics" and is noncommittal and very personalized. This 
definition is more forgiving and neutral compared to Kristofferson et. al.'s (2013), as it does not evaluate slacktivism in the very definition of the term. Describing clicktivism as a variety of "low-threshold activities" is fair, as the ease of use is what makes clicktivism so appealing and widely accessible. Clicktivism can be performed by anyone anywhere with an Internet connection, giving the general public the freedom to partake in political activities that they may not have had the time, skills, or funds to do otherwise. Halupka's (2018) description of clicktivism does, however, raise questions about what might be considered "engag[ing] in politics," and how to do so effectively. If we draw upon Leyva's (2017) definition of slacktivism, it provides multiple reasons why someone may share a Facebook post about a social issue or political event. Even if the sole purpose of engaging with such posts allows only a small form of satisfaction to the individual, their identity is subsequently affirmed as a good socially and politically aware citizen. Clicktivism is a simple concept with a variety of outcomes, both big and small, which all come together to incite change.

\section{Hacktivism}

A form of slacktivism that is used by a relatively small group of people but can have enormous immediate results is known as hacktivism. Hacktivism refers to the use of computers and technology to promote a political or social message, usually by exerting strong and immediate pressure on the government or corporations (Veil, Reno, Freihaut and Oldham, 2014). Usually when media outlets discuss hacktivists like the group known as "Anonymous," it is done so with a very negative connotation as most forms of hacktivism are illegal. This is another case of a particular term being deemed negative simply due to its etymological composition that, of course, has been socially constructed. In this case, the combination of the words "hacker" and 
Piat

"activism" imply that in order to be a "hacktivist," you must be committing some type of cybercrime.

Although hacking certainly does exist within the realm of hacktivism, Veil et. al. (2014) shed light on forms of 'social media hijacking' that do not necessarily have to be done through illegal means. Coleman (2017) claims that hacktivists do not require any technical skills, though being a "geek" is useful. A geek can be anyone who has basic computer skills which unfortunately does not include a large part of the global population. However, the expansion of readily available open-comment forums and anonymous websites allows individuals with very little technological knowledge are able to "take over" websites and pages. Hackers can work alone or communally in order to incite change for a particular cause. Individuals can participate in lower-scale hacktivism like flooding websites' comment sections, an activity that requires very little computer skills, but Coleman (2017) points out that these actions are often strengthened by coinciding high-risk hacking activity. Some may be inclined to question whether both forms of hacktivism are even necessary, which we will explore in this paper. When illegal hacktivism is done "correctly," it is completely anonymous and can make a huge immediate impact, as seen in the case of the WikiLeaks scandal (Coleman, 2017). Illegal forms of hacktivism, however, are not accessible to the layman who does not have expert-level computer skills, possibly impacting which causes are brought to the attention of authority and which causes are ignored.

\section{Is Slacktivism Effective Activism?}

\section{The Effectiveness of Hacktivism}

Hacktivism remains solely in the online sphere and tends to have large and quick results 
compared to more low-scale clicktivism actions. Veil et. al. (2014) discuss a case of social media hijacking that could be considered slacktivism, but did result in tangible change. A hoax blog post against Kraft directed attention to a real campaign against potentially dangerous dyes in some of Kraft's products. Though the initial post ended up having false and unethical information, Kraft eventually removed the potentially harmful ingredients. Despite hacktivism having the potential to lead to tangible results in terms of government or social change, I fear that it may never be accepted as legitimate in terms of public approval. Currently, if there is a protest for a legitimate cause, as soon as any form of civilian violence or property damage occurs, many media outlets and individual citizens alike immediately discredit the movement as a whole. There is a strong general public contempt for law-breaking in conjunction with social movements, and the fact that hacktivism is, by definition, an illegal act, implies that it may not be able to have the full reach we need.

\section{How is Effectiveness Determined?}

A common criticism of slacktivism is that it "doesn't do anything," but we must deconstruct what "doing something" really means. From a "dutiful citizen" perspective that promotes traditional democratic values like voting and lobbying, of course slacktivism appears to be nothing more than leisurely conversation and activity. Some may argue that online forms of activism like tweeting, posting, sharing, and liking are on the same level as online activities that are only entertainment-based. However, the Internet is rapidly evolving, changing the way we interact with websites and each other in the online arena. Slacktivism is a complex field of study, as researchers' work becomes outdated as quickly as they can publish it. Particular websites shift in and out of popularity, and what was once used as a political platform is no 
Piat

longer used in such a fashion. Furthermore, it is difficult for one single study to make broad, global conclusions about slacktivism as different countries have access to different social media websites. For example, Leyva (2017) found that UK youth that regularly engage with political content have relatively low levels of offline participation and higher levels of slacktivism (ie: online engagement). Leyva (2017) describes this as a rather bleak future in which we live; however, it is important to keep in mind that increased online activity alone is not inherently an ineffective form of activism. Boulianne's (2015) meta-analysis of global slacktivism that included results from 36 different studies showed that, on average, engaging with politics and social issues online is correlated with engaging in these issues offline. Direct unidirectional causation is unclear, though it simply does not matter in this case. For opponents of slacktivism focussing their critiques on the assumption that slacktivists do not engage in more traditional forms of engagement, Boulianne's (2015) data are critical to consider.

\section{Context is Key}

Context is everything when it comes to clicktivism. Any action can either be political or non-political depending on its context. Halupka (2018) uses the example of someone in America versus someone in Saudi Arabia interacting with an online post about Britney Spears. The same action in two different contexts is either an ordinary online behaviour or deeply political and potentially dangerous. Context is not only established by location, however. Perhaps even more important is the intention behind the online act. Halupka (2018) sheds light on all of the small context cues like vocal tone and body language that are lost in online spheres, leading us to rely solely on an online act's content and one's own opinion of the actor to determine intention. If we cannot determine intention, it becomes increasingly difficult to determine the political nature of 
an online act, thus rendering it potentially illegitimate. This is likely even more relevant when a young person is engaging with politics online, since the public perception of millennials is that they are uncaring, disengaged, and lazy. When taken at face value, an online post with an ambiguous intention may be confusing at best, and disregarded at worst. However, this position does not consider the ease and accessibility of online conversation that may arise from ambiguous situations. A tweet is not fired out into the ether to exist all on its own. That is what makes online spheres so unique and accessible. Individuals, often shielded by anonymity, have the ability to interact with online posts, posing questions for clarity and sharing their own opinions. This type of engagement differs from traditional media like newspapers, as we now have the ability to read a post, immediately respond, and sometimes engage in an immediate conversation. Halupka (2018) is correct in asserting that intention is important to politicize online acts, but the lack of clear intention does not leave acts meaningless if individuals are willing to engage with each other. Halupka (2018) draws on an international study (Halupka, Bang, Jensen and Ercan, 2015) shows that the majority of people have negative perceptions about clicktivism, while rates of clicktivism remain very high. The disconnect between the high popularity of clicktivism and the perception that it will not actually lead to legitimate change leads us to question why people engage in clicktivism in the first place. It is possible that they feel ashamed of their own slacktivism and feel pressured to denounce it thanks to notorious public figures media. Low-scale personal reasons of spreading information, showing support with a 'like,' and affirming one's identity are certainly legitimate enough reasons to engage in politics online. 
Piat

\section{Motivations Behind Slacktivism}

Keeping the concept of context in the forefront, the motivations for individuals to partake in slacktivism are as nuanced and varied as the many definitions of slacktivism. Chapman and Coffé (2016) conducted a study with a sample of Facebook users under the age of 35 to determine the reasons behind changing one's profile picture for a particular cause. The types of campaigns that users engaged with most frequently included 'Pre-election party or issue,' 'Blackout,' 'Marriage equality,' and 'Breast cancer.' The issues listed are clearly global in nature, addressing subjects like copyright infringement laws, political parties, and social issues. Chapman and Coffé (2016) found that the leading motivations for updating a profile picture for a cause was the desire to raise awareness, that the action aligned with the individual's identity, and the belief that the action was easy and may have an impact. Generally speaking, individuals who partake in this small form of activism tend to believe that it may make some kind of change, whether that be through spreading a message or perhaps through mobilizing others to act offline. Again, the concept of identity formation and personal satisfaction arises as one of the driving forces behind slacktivism. When performing a small and simple action makes us feel good and confirms that we are, indeed, good people who want to make change, we are likely to continue engaging in that action.

It is important to note that the sample used in Chapman and Coffé's (2016) study was relatively small and that university educated, politically interested, left-wing youths in New Zealand were overrepresented. Looking at the types of social issues that were being supported by this group of students, the demographic should not come as a surprise. Typically, in sociological studies about slacktivism, this kind of convenience sample is common. It would be of worth to engage with right-wing youths and compare how identity formation plays a role in 
their rates of online activism. Chapman and Coffé (2016) conclude that online and offline engagement overlap greatly, meaning that those who participate in offline protests and boycotts for example, are likely to change their Facebook profile picture for a cause. These results coincide with Boulianne's (2015) meta-data, illustrating that regardless of the causal direction, offline and online participation go hand in hand. This should, hopefully, give critics of slacktivism pause and dissuade them from assuming young online activists are not participating offline as well.

\section{The Informed Citizen and the Slacktivist}

To further illustrate Chapman and Coffé's (2016) point, Kliger-Vilenchik and Thorson (2016) investigated the two battling frames of engagement that are "the slacktivist" and "the informed (also known as dutiful) citizen." So-called informed citizens differ from the slacktivist as they keep up to date on current events and traditional news media, they vote in elections, and they bring any social or political issues forwards to their Members of Parliament (MP). There is a very clear power structure in the informed citizen model whereby all of the power is held by the government while citizens are left with no option but to trust that politicians will act in accordance with their best interests. This concept often leaves citizens feeling unheard, unvalued, and unable to incite change, especially when their MPs are part of a party that opposes a citizen's own values.

Of course, things like voting and staying informed about current politics are important and cannot be abolished completely simply because the overall structure of the informed citizen is flawed. Modern democracy still relies heavily on these things, at least presently. Pundits of both the slacktivist frame and the informed citizen frame criticize the effectiveness of the other, 
Piat

but Kliger-Vilenchik and Thorson (2016) claim that space exists for a theoretical framework that combines each concept. As determined by Chapman and Coffé's (2016) and Boulianne (2015), it is clear that we have already moved past the theoretical realm and activists are, in fact, combining slacktivism and dutiful citizen actions.

\section{Slacktivism's Accessibility and Ease of Use}

Gladwell (2010) claims that online petitions are so effective at collecting large numbers of signatures because they are asking so little of citizens. The act of signing an online petition requires such little thought, effort, and time compared to large-scale protests such as those occurring during the Civil Rights Movement, and Gladwell (2010) asserts that online activists do not understand the difference between these actions. It is easy to think of young activist clicking "like" on an online call to action and clearing themselves of further responsibility when we have figures of authority in science, politics, and media, such as Gladwell, painting this picture for us. However, Boulianne (2015) found that this is simply not the case. Small acts of online engagement do, in fact, correspond to significant offline action. On a more extreme level compared to Gladwell (2010), Morozov (2009) boldly claims that "slacktivism is the ideal type of activism for a lazy generation." He claims that slacktivism is dangerous as it allows online activists to believe they are doing something useful with very little effort and political impact. This is an unfair and inaccurate position, however, especially considering Chapman and Coffé's (2016) and Boulianne's (2015) evidence that indicates a strong correlation between online and offline participation. While considering this correlation, we must not think of slacktivism as simply a means to a dutiful citizen end. Young people who engage in online activism are far from lazy, even if their main motivation for activism is to raise awareness or strengthen their 
identities. These factors are not inherently negative simply because they do not involve a powerful figure such as an MP. Online activism centres around community, both local and global, and the strength in numbers cannot be ignored, especially when we observe the tangible results of recent movements like \#TimesUp.

\section{The Impact of Relationships}

The realm of the Internet serves to build new relationships and strengthen new ones. We can reach people from around the world and share our personal stories that may compel others to act, perhaps if they believe it will strengthen their identities. Connections are important, this I cannot deny, but in-person connections are not the sole form of contact that we have with our peers anymore. Gladwell (2010) claims that close-knit personal relationships are the backbone of social movements, as we are encouraged to participate in causes if our trusted social networks call us to action. He claims that on the Internet, followings have replaced strong friendships, and our ties to community are loosened. This is not necessarily a negative progression though, as Graeff (2016) discusses. Young people are growing more and more dissatisfied as their needs, concerns, and values are not reflected in traditional political spheres. Youths are rejecting the classic dutiful citizen model that prides itself in voting and respect for government authority, and are instead "crowdsourcing" problem solving using loose ties. While crowdsourcing with socalled "loose" connections - such as the Facebook profile picture movements - certainly does occur and have its benefits, there appears to be a disconnect between academics and the subjects whom they study. Gone are the days of not knowing who is on the other side of your computer screen. Close, tightknit communities are formed on the Internet and even transport themselves into the "real world" of local communities. Issue-oriented activism such as the Occupy 
Piat

movement (Graeff, 2016) or the \#MeToo movement began online and mobilized offline global communities. The outcome of these activities certainly cannot be ignored, and it was a result of trusted peer groups listening to each other and responding to issues that spoke to them personally.

\section{Is Identity Formation Enough?}

The topic of identity formation as a motivating factor for activism is somewhat contentious. Many believe that so-called 'identity politics' are ruining modern democracy as people are banding together based on their shared values or backgrounds rather than political parties and have no hope of inciting real change using this method. I believe this is simply another fear-mongering tactic from pundits of the 'dutiful citizen' sphere. As Graeff (2016) mentioned, youth are feeling underrepresented and ignored by traditional political parties, and banding together based on identity is clearly a satisfactory mobilizing strategy.

Kristofferson et al. (2016), found that individuals who made a small charitable donation in public were less likely to make a subsequent donation compared to those who made their donation in private. This is likely due to the fact that those who made their donations in private felt that the act affirmed their identity as someone who believes in the cause, or even simply their identity as a good person. Furthermore, Kristofferson et. al. (2016), identified that when individuals who made a public donation were able to focus on their personal identities and how they aligned with the cause, they were then more likely to make a subsequent, and often "more meaningful" contribution to the cause. These results show that regardless of the initial circumstances of a political act, engaging with one's identity is a motivating factor in further engagement. 
Slacktivism

\section{Who Must be Involved in Slacktivism in Order to Legitimize it?}

We should be wary of who is given the authority to deem particular political acts legitimate or not. Does participation have to result in new bills being passed? Do members of parliament have to be involved? If someone cannot afford to make a large donation to a cause, is their small donation deemed ineffective? Can doing something simply to boost your own ego and feel as though you've made a difference be considered effective? I would argue that even the smallest action that exists only to affirm someone's identity as an activist is a legitimate political action, especially given the results of Kristofferson et. al.'s (2016) study. Hay (2014) claims that political action is legitimate once it moves from the personal sphere, to the public sphere, to the governmental sphere, and that this movement is most effectively performed through traditional means of engagement. Issues that exist solely in the private sphere must become "politicised" in order for governments to acknowledge them as important for the common good (Hay, 2014). This position, again, relies on the involvement of government authorities to legitimize an issue. Knowing what we know about politics, those in power are often of the most privileged classes and may not see value in issues brought to them. If an authority figure must be involved, then we must not ignore the fact that politicization occurs online as well. If millions of people change their Facebook profile picture, they draw the attention of the media and political authorities. A sort of power is garnered as a result of these large-scale easy actions, as they serve to exert pressure on lawmakers.

Halupka (2018) draws attention the fact that social media websites have been transformed from their original purpose as their users discover and create new ways to engage politically. To an outsider, if something like a "Facebook revolution" is in the news, it might feel natural to dismiss it - especially if young people are involved. Halupka (2018) points out that critics might 
Piat

claim that clicktivism is politically-themed, but since it does not exist within the political realm, it is deemed ineffective and illegitimate. They posit that the integral part of legitimacy that is connecting the individual to the political authority is lost. However, even political actors and social leaders and groups are inhabiting more and more digital spaces. There are livestreams of talks, Reddit Q\&As, and even everyday tweets from the Prime Minister that draw public engagement. If we consider crowd turnout at a rally or political speech a good indication of public support and engagement, we should legitimize YouTube views and Twitter likes in the same way. There, of course, is the issue of dummy or "bot" accounts on social media websites that may skew the numbers, but we must also consider how the Internet draws more and more people in, making information much more accessible to a greater number of people.

Furthermore, someone replying to Justin Trudeau's tweets may not necessarily receive a response from him specifically, but they are granted the space to voice their opinions and possibly garner their own supportive network.

Activism exists on a spectrum. It can range anywhere from praying to protesting to corporate disinvestment. It would be naïve to argue that changing your Facebook profile picture has the same outcome as a widespread international protest or boycott. However, just because an action is less effective than another action does not mean we should not do it. Imagine if we all collectively stopped recycling plastic water bottles because that action is less effective than rallying for the government to invest in renewable energy. Engaging in online activism may perhaps lead people to believe they've 'done enough' and do not need to engage further. For some, slacktivism is highly performative and publically showing that we care about an issue may not actually benefit the cause, as Kristofferson et. al. (2016) argue. However, online activism is 


\section{Slacktivism}

highly accessible to almost everyone, people are free to share their opinions or the opinions of others, and engage in discussion with people outside of their immediate offline network. Each action is worthwhile and effective, even if they require different difficulty levels and result in a wide range of outcomes. 
Piat

\section{References}

Boulianne, S. (2015). Social media use and participation: A meta-analysis of current research. Information, Communication \& Society, 18(5), 524-538, doi: 10.1080/1369118X.2015.1008542

Chapman, H., Coffé, H. (2016). Changing Facebook profile pictures as part of a campaign: Who does it and why? Journal of Youth Studies, 19(4), 483-500.

Coleman, G. (2017). From Internet farming to weapons of the geek. Current Anthropology, 58(15), 91-102.

Gladwell, M. (2010, October 4). Small change: Why the revolution will not be tweeted. The New Yorker. Retrieved from: https://www.newyorker.com/magazine/2010/10/04/small-changemalcolm-gladwell

Graeff, E. (2016). Youth Digital Activism. Retrieved from: https://www.academia.edu/27108947/Youth_Digital_Activism_UN_World_Youth_Report. 95-106.

Halupka, M., Bang, H., Jensen, M., \& Ercan, S. (2015). Global Protest Project Report, Institute for Governance and Policy Analysis. Canberra: University of Canberra.

Halupka, M. (2018). The legitimisation of clicktivism. Australian Journal of Political Science, 53(1), 130-141.

Hay, C. (2014). Depoliticisation as process, governance as practice: What did the 'first wave' get wrong and do we need a 'second wave' to put it right? Policy \& Politics, 42(2), 293-311.

Kliger-Vilenchik, N., \& Thorson, K. (2016). Good citizenship as a frame contest: Kony2012, memes, and critiques of the networked citizen. New Media \& Society, 18(9), 1993-2011.

Kristofferson, K., White, K., \& Peloza, J. (2014). The nature of slacktivism: How the social Observability of an initial act of token support affects subsequent prosocial action. Journal of Consumer Research, Inc, 40, 1149-1166.

Leyva, R. (2017). Exploring UK millennials' social media consumption patterns and participation in elections, activism, and "slacktivism." Social Science Computer Review, 35(4), 462-479.

Morozov, E. (2009, May 19). The brave new world of slacktivism. Foreign Policy. Retrieved from http://foreignpolicy.com/2009/05/19/the-brave-new-world-of-slacktivism/

UNICEF Sweden. (2013). “Likes don’t save lives” promotional campaign. Retrieved from http://unicef.se/

Veil, S. R., Reno, J., Freihaut, R., Oldham, J. (2015). Online activists vs. Kraft foods: A case of social media hijacking. Public Relations Review, 41, 103-108. 